\title{
LOS UNIVERSALES CULTURALES *
}

JOHN PASSMORE

The Research School of Social Sciences The Australian National University

Con frecuencia a los filósofos se les ha acusado de tratar de establecer, por medio de una reflexión a priori, cuestiones que no pueden establecerse sino a través de la observación empírica. ¿Acaso no nos exponemos a esa acusación si, como filósofos, nos suponemos capaces de arrojar cierta luz o, lo que es peor aún, de zanjar el problema de la existencia de los universales culturales? Eso afirmarían tanto los múltiples amigos de la filosofía, como sus enemigos. Los amigos de la filosofía nos acusarían de desprestigiarla, al hablar en su nombre de cuestiones que están fuera de su ámbito; sus enemigos sostendrían, en cambio, que, como nos es característico, no logramos ver que las ciencias sociales -en este caso, la antropologíapueden ofrecer ahora respuestas positivas ahí donde la filosofía no podía sino especular o, lo que es peor, ocultar su ignorancia bajo el manto del dogmatismo.

Supongo que habría dado lugar al escándalo el que yo hubiera empezado aceptando con entusiasmo este punto de vista y procediera después a dar las razones que me llevaron a actuar de ese modo. Sin embargo, tengo que confesar que en ocasiones me sentí inclinado a hacer precisamente eso. Después de todo, cuando el otro día quise saber si la música era un universal cultural, ¿a quién acudí para resolver mi duda? ¿A un filósofo? Por supuesto que no: acudí a un antropólogo. Y la situación habría sido exactamente la misma de haberse puesto en cuestión cualquier otro ejemplo. $\mathrm{O}$ así lo creí en un principio.

Gradualmente, sin embargo, empecé a darme cuenta de que esto no es enteramente cierto, de que había casos en que el antropólogo no tenía la última palabra. Bajo otras formas, también, la relevancia de la filosofía en cuanto al problema de los universales culturales empezó a manifestarse, aun cuando en algunos aspectos, bastante

* Ponencia presentada en el XVIII Congreso Mundial de Filosofía que tuvo lugar en Brighton, Inglaterra. 
vitales por cierto, persistía la necesidad de recurrir a la antropología. Así que finalmente decidí emprender, no la demostración de que la filosofía nada tiene que decir acerca de los universales culturales, sino más bien la determinación de qué es lo que tiene que decir y en qué aspectos debe permanecer callada.

Hagamos primero una pregunta preliminar. ¿Qué significa afirmar, o negar, que hay universales culturales? Preguntas del tipo “¿qué significa?" resultan con frecuencia artificiosas, y entorpecen la investigación en lugar de adelantarla. No obstante, no es este el caso. Y es que la palabra "cultura", al igual que ciertas expresiones similares de otras lenguas, es notoriamente ambigua. Ya Herder se quejaba, en estos términos, acerca del término alemán "Kultur"; la diligencia de dos antropólogos norteamericanos descubrió no menos de 164 definiciones diferentes de la palabra inglesa. Y no es necesario decirles a los filósofos qué problemas se hallan ligados a la palabra "universales".

Empecemos con la palabra "cultura"; dividiremos crudamente sus múltiples usos, en una forma ahora familiar, en dos grupos -aquellos usos que caracterizan a la investigación socio-antropológica, y aquellos que tradicionalmente emplean los humanistas. Para el socioantropólogo, la cultura de una persona la forman todos los hábitos, actitudes, modos de actuar, intereses, juicios, sistemas de creencia, adquiridos por dicha persona en cuanto miembro de una sociedad nacional particular o de un subgrupo de esa sociedad. Es aquello que, independientemente de la apariencia personal, permite reconocer a una persona como inglesa, hindú, francesa o mexicana. $Y$ dentro de estas sociedades, lo que permite que sea reconocida como granjero de Yorkshire, príncipe hindú, cocinero francés o músico mexicano. La cultura de una persona, en este sentido de la palabra, se adquiere, en gran parte, mediante un proceso de ósmosis, aunque puede reforzarse gracias a un entrenamiento intencional.

Mientras que en el uso antropológico sólo se discrimina entre grupos sociales, la antítesis "culto"/"inculto" es utilizada por los humanistas para distinguir entre los diferentes miembros individuales de esos grupos. Todo el mundo sufre transformaciones por asimilación cultural, pero un doctor, un granjero o un inglés, pueden ser cultos o incultos. La característica central de las personas cultas, desde el punto de vista del humanista tradicional -añado el adjetivo "tradicional" pues hoy en día muchos de los que trabajan en las áreas tradicionalmente humanísticas apenas pueden distinguirse de los socio-antropólogos-, reside en su entendimiento y apreciación de los logros intelectuales y artísticos tanto de su país como de los demás. 
$\mathrm{Si}$ "cultura" es lo que propiamente puede pretender poseer dicha persona culta, obviamente esa cultura no es universal, como tampoco puede encontrarse en todas las sociedades de todos los tiempos. Puede empezar a existir sólo en esa fase del desarrollo de la civilización en el que las sociedades humanas entran en relaciones complejas distintas de la guerra. Puede sin embargo argumentarse que hoy en día las personas cultas pueden surgir en cualquier sociedad; las barreras físicas de la comunicación han sido abolidas, las reproducciones masivas ponen los más importantes logros artísticos e intelectuales del mundo al alcance de todos. Pero aun en algunas sociedades contemporáneas, la pobreza, la guerra, la censura, pueden desvanecer casi por completo la posibilidad de adquirir una cultura de tipo humanista. Como nos lo recuerdan vívidamente Alemania en tiempos de Hitler y China en tiempos de los guardias rojos, este tipo de cultura puede ser atacada incluso en países que alguna vez la poseyeron en alto grado. En todo caso, no nos interesan las formas de cultura que sólo existen en ciertos lugares y ciertas épocas; nos interesan las universales. Podríamos esperar que algún día hubiera personas cultas en todas partes; poniéndonos utopistas, podríamos incluso esperar que la antítesis "culto" e "inculto" no tuviese ya ningún punto de referencia. Pero se requiere tan sólo de un ápice de conocimiento histórico, y no de agudeza filosófica, para concluir que, de acuerdo con esta definición, no se encontrarán personas cultas a lo largo del tiempo en todas las sociedades.

Pero, ¿qué hay de las actividades en que centran su atención las personas cultas - las artes, la filosofía, la actividad académica, la investigación científica-, y que para ellas comúnmente son las que conforman la cultura de una sociedad? ¿Tendría la filosofía algo interesante que decir si se planteara la pregunta de si aquéllas son universales?

Empecé admitiendo que cuando quise saber si la música era un universal cultural, recurrí a un antropólogo, y no a un filósofo. Eso sería también lo mejor que podría hacer si quisiera saber si en todas las sociedades se cuentan cuentos. Pero también sugerí que en algunos de esos casos la palabra del antropólogo podría no ser la última. Supongamos que, a mi pregunta sobre la narración de cuentos, el antropólogo respondiera directamente: "Sí, y en todas las sociedades algunos de esos cuentos son científicos, otros filosóficos y otros históricos". No tomaría esta respuesta como la solución al problema de si la ciencia, la filosofía y la historia son universales culturales. Le pido ejemplos al antropólogo. Él me cuenta cuentos; no puedo, simplemente, como filósofo, saber si de hecho los cuenta correctamente o 
no. Pero ciertamente es una cuestión filosófica saber si estos cuentos se clasifican como historia, filosofía o ciencia.

Por supuesto, es una cuestión que comprensiblemente el filósofo trataría de evitar, a sabiendas de que una respuesta negativa podría provocar las acusaciones más implacables - elitismo, racismo, neocolonialismo. Pero no es más elitista decir que la mitología difiere de la filosofía, que decir que la tiza difiere del queso, aun cuando ambos están compuestos de calcio; no es racista negar que las crónicas anglosajonas o los Nihon-shoki japoneses son considerados historia, a pesar de lo invaluables que son para los historiadores; no es neocolonialista afirmar que los británicos aprendieron filosofía de los romanos o los norteamericanos de los británicos.

Las acusaciones de racismo y elitismo no contribuyen en nada a la solución del problema; no son argumentos sino substitutos de argumentos. Para resolver estos problemas, es mejor examinar de cerca la manera en que la historia difiere tanto de la ficción como de las crónicas; la forma como la ciencia se distingue tanto de la sabiduría práctica como de la mitología; el modo como la filosofía difiere de las afirmaciones generales sobre el lugar que ocupan los seres humanos en la naturaleza. Para tratar de justificar estas distinciones uno se ve forzado a examinar cuestiones relativas a la evidencia, la crítica, la objetividad -en pocas palabras, los problemas fundamentales de la epistemología.

Por lo tanto, llegados a este punto, las concepciones particulares sobre lo que es y no es un universal cultural pueden acercarnos al corazón de la filosofía. De hecno, la existencia misma de la filosofía, como forma diferenciada de investigación, se encuentra comprometida. Porque si está tan deficientemente definida como para incluir cualquier forma de especulación, de manera que la discusión crítica ya no reside en su centro - como ciertamente tampoco reside en el centro de la mitología o de la sabiduría práctica - la razón misma de su existencia desaparece. Definiciones deficientes como ésa son características del intento por convertir en universales las actividades culturales, cuando la evidencia demuestra con toda claridad, en la acepción ordinaria, que obviamente no lo son.

He sugerido, pues, que hay aspectos en los que la filosofía está relacionada con el problema de si hay universales culturales en el sentido humanista de la palabra "cultura". Analicemos ahora el sentido socio-antropológico de la palabra. Hacerlo nos obligará a un examen, más minucioso que el que hemos hecho hasta ahora, de las condiciones que han de cumplirse antes de que podamos calificar adecuadamente a una forma particular de cultura como "universal". Dado que antropológicamente utilizamos el concepto de cultura como una 
forma de distinguir entre sociedades y subgrupos sociales, podría pensarse que no es necesaria mayor discusión. Sencillamente, el poseer una cultura particular es lo que distingue a una sociedad de otra; de ahí que, por la naturaleza del caso, no puede haber universales culturales ya que éstos no podrían emplearse para establecer distinciones. Pero éste resultaría un argumento demasiado fácil.

Tomemos un caso comparable. Con frecuencia usamos la estatura como una forma de distinguir a los seres humanos -en las descripciones que se hacen a la policía, por ejemplo. Sin embargo, la estatura es un universal biológico humano en el sentido de que siempre hay una respuesta a la pregunta: "¿Qué estatura tiene esa persona?". Y no sólo eso. Aunque los seres humanos difieren considerablemente en estatura, no podrían sobrevivir si tuvieran una estatura menor o mayor de cierta medida. Tanto Pulgarcito como los gigantes son sólo criaturas de ficción. (No pretendo decir, por supuesto, que esto es algo que puede descubrirse mediante razonamiento filosófico.) Tenemos así como verdad universal el postulado: "Todo ser humano maduro mide entre $x$ y $y$ metros". ¿Existe algo similar en el caso de las características culturales?

Permítaseme empezar, en el sentido de este ejemplo, distinguiendo entre una interpretación rigurosa, una laxa y otra rígida de la expresión "universales culturales" en su sentido socio-antropológico. Una interpretación "rigurosa" no permitirá la existencia de universales culturales a menos que ocurra precisamente el mismo fenómeno cultural en todos los tiempos y en todas las sociedades - como si la "estatura" pudiera describirse como un universal humano sólo si los seres humanos tuvieran exactamente la misma estatura en todas partes. La crítica socio-antropológica de los universales culturales con frecuencia acepta tácitamente esta interpretación. Se contenta con señalar la enorme variabilidad entre las sociedades humanas aun con respecto a las reglas relacionadas con imperativos biológicos universales tales como el cuidado de los bebés, la atención a los muertos, las relaciones sexuales, sin las cuales ninguna sociedad podría sobrevivir, para no mencionar las reglas que gobiernan fenómenos culturales tales como las lenguas.

Estas observaciones antropológicas, en la medida en que son válidas, resultan fatales para la interpretación rigurosa de la concepción que sostiene la existencia de universales culturales. Pero no destruyen la interpretación "laxa" - según la cual existen universales culturales si ciertos tipos de actividad humana se encuentran en alguna forma en todas las sociedades, sin importar cuán variables sean. En este sentido, hay universales culturales si el antropólogo puede visitar cualquier sociedad, en cualquier lugar y en cualquier época, 
con la seguridad de encontrar respuestas positivas a preguntas tales como: "¿Qué lengua se habla ahí?", “Cómo cocinan sus alimentos?", “Qué procreaciones prohíben?", “Qué cuentos cuentan?”, “Cómo ponen fin a las disputas?", ¿Quién cuida de los bebés?". Empleando esta interpretación laxa, un antropólogo norteamericano confeccionó una lista de unas setenta categorías de comportamiento que, según afirma, se han registrado en toda sociedad, aunque, por supuesto, no necesariamente caracterizan a todos los miembros de esa sociedad. No todos bromean, pero en todas las sociedades, aun las más lúgubremente puritanas, parecería que en alguna forma se hacen bromas. Así como todo ser humano tiene cierta estatura, así también toda sociedad permite que se hagan bromas hasta cierto punto sobre temas de cierto tipo.

La interpretación "rígida" es más exigente que la anterior, aunque no tanto como la interpretación "rigurosa"; coincide con el punto de vista según el cual todas las estaturas humanas varían dentro de cierto rango. Un claro ejemplo es la teoría de los "universales lingüísticos" desarrollada por Chomsky y sus seguidores. Chomsky sostiene que si bien las lenguas obviamente difieren en gran medida de una cultura a otra, tienen más elementos comunes que el solo hecho de ser todas ellas lenguas. Así que, de entre la gama de sonidos que los seres humanos podrían producir, ciertos sonidos no se utilizan de hecho en ninguna lengua, e igualmente, se da una selección entre lo que parecería ser, hablando en abstracto, mecanismos sintácticos posibles. En un espíritu similar, alguien podría tratar de apoyar el punto de vista según el cual las reglas en contra del incesto son universales culturales, argumentando que a pesar de que las relaciones familiares prohibidas varían enormemente de una sociedad a otra, las relaciones prohibidas son sin embargo sólo de cierto tipo. De tal suerte que el incesto sería un universal rígido y no riguroso.

Lo que he hecho hasta aquí - establecer algunas distinciones para aclarar los puntos que deben considerarse en una controversia- es, me parece, una tarea propiamente filosófica. No obstante, no contribuye, en sí mismo, a mostrar que hay, de hecho, universales culturales rigurosos, laxos o rígidos, y menos a mostrar qué son. Parecería, hasta ahora, que esta tarea le corresponde a los antropólogos o a los lingüistas. Sin embargo, uno se da cuenta de que cuando Chomsky intentaba establecer sus teorías lingüísticas, recurrió a Descartes y al platónico de Cambridge, Ralph Cudworth. ¿Cómo fue que esos filósofos entraron en escena?

Al discutir la cultura humanista de las personas cultas, dije que para que esta cultura pueda ser considerada universal, tendría que estar presente en alguna forma en todas las sociedades de todos los 
tiempos. Esa frase, quiero subrayarlo ahora, comprende no sólo el pasado y el presente sino también el futuro. Es por ello que los reformadores sociales radicales se oponen con frecuencia a la idea de que hay universales culturales; esta idea fija límites al cambio social. Tales reformadores atacan repetidamente el concepto poniendo como ejemplo el caso de sociedades pasadas o presentes en las que no se encuentra el presunto universal. Así, Marx, apoyándose en los antropólogos, recurre al comunismo primitivo para impugnar la idea de que la propiedad privada es universal. Alternativamente, el reformador radical puede hacer la descripción de una utopía en la que, juzgando únicamente a partir de la experiencia pasada, lo que odríamos pensar como un universal cultural simplemente no existe.

Para oponerse a semejantes contraejemplos, sean éstos reales, supuestos o imaginados, el defensor de los universales culturales irá naturalmente en busca de una teoría que no sólo explique por qué en el pasado algunos fenómenos culturales han estado presentes constantemente en las sociedades humanas, sino que también suministre bases más firmes, algo más sólido que una mera apelación a lo que ha sucedido en el pasado, para justificar la predicción de que estos mismos fenómenos ocurrirán en el futuro.

Una teoría semejante puede adoptar un número indefinido de formas. Al rechazar la tajante dicotomía naturaleza/cultura, los sociobiólogos señalan los parecidos entre las sociedades humanas y las no humanas, partiendo de ahí para explicar en términos neodarwinianos, la razón exacta por la que fenómenos como la prohibición del incesto entre hermanos, se encuentran no sólo en las sociedades humanas, sino también en muchas sociedades animales. (Sus argumentos plantean problemas filosóficos fundamentales, y no es sorprendente que los filósofos, particularmente Bernard Williams, hayan contribuido al debate socio-biológico.)

En términos más generales, se puede argumentar que la repetición constante de ciertos fenómenos culturales, ya sea en una forma rigurosa, ya en una forma laxa, no puede comprenderse a menos que supongamos que los seres humanos se inclinan en forma innata por ciertos modos de conducta, aun cuando éstos no varíen sino dentro de un cierto rango. (La interpretación rígida.) Ahora bien, John Locke sostuvo que nada en los seres humanos es innato con excepción del impulso para buscar el placer y evitar el dolor. Mientras tanto, sus argumentos alentaron a los reformadores, particularmente cuando, en sus escritos teológicos, dirigió sus ataques contra el concepto de pecado original. Chomsky afirma que las objeciones de Locke a lo innato sólo se aplican a las teorías primitivas sobre las ideas innatas; y busca en Descartes y Cudworth una teoría mejor. De hecho, buen 
número de nociones sobre lo innato son relevantes para el tema que nos ocupa; lo que se considera innato puede ser un impulso, como lo fue para Hume, o formas de organizar nuestro mundo, como lo fue para Kant; o una aversión a hacer cierto tipo de cosas - como por ejemplo, tener relaciones sexuales con personas con quienes uno creció durante los primeros seis años de vida-o, si Chomsky tiene razón, una habilidad para aprender cierta clase de cosas pero no otras. Cada una de estas teorías puede utilizarse para explicar, la existencia de universales culturales, y predecir su continuada existencia.

Resulta claro, entonces, que el intento por demostrar la existencia de los universales culturales, y por explicar la razón por la que adoptan una forma particular, puede llevarnos al fondo de los problemas epistemológicos tradicionales. Por supuesto, tenemos que enfrentarnos a la objeción de que mientras haya aquí problemas reales, éstos sólo podrán encararse, digamos, mediante investigaciones psicológicas sobre el comportamiento de mellizos idénticos que fueron separados al nacer. Cuando las ciencias sociales, a las que tanto contribuyeron en un principio, empezaron a adoptar un cariz profesional, se manifestó entre los filósofos, particularmente en el mundo anglo-americano, una tendencia a replegarse hacia un campo temático más limitado, dejando muchos de sus problemas tradicionales en las entusiastas y confiadas manos de la ciencia social. Pero en la actualidad se ha vuelto claro que la reflexión filosófica es todavía necesaria en el campo de las ciencias sociales. Esto no significa que el filósofo puede llegar al campo de las ciencias sociales desde fuera y poner en orden las cosas. Tiene que estar preparado para estudiar los logros alcanzados por los científicos sociales, incluyendo también bajo este título a los psicólogos. Hay cada vez más indicios de que esto está ocurriendo, particularmente en relación con el problema epistemológico que he estado esbozando. Todo lo que he dicho podría sugerir, en términos más generales, que la cuestión de los universales culturales es un problema de ese tipo. Sería muy erróneo afirmar que los filósofos no tienen nada que aportar; tan erróneo como afirmar que la filosofía puede, por sí sola, zanjar la cuestión. 